\title{
Montelukast Sodium
}

National Cancer Institute

\section{Source}

National Cancer Institute. Montelukast Sodium. NCI Thesaurus. Code C47625.

The orally bioavailable monosodium salt of montelukast, a selective cysteinyl leukotriene receptor antagonist with anti-inflammatory and bronchodilating activities. Montelukast selectively and competitively blocks the cysteinyl leukotriene 1 (CysLT 1) receptor, preventing binding of the inflammatory mediator leukotriene D4 (LTD4). Inhibition of LTD4 activity results in inhibition of leukotriene-mediated inflammatory events including: migration of eosinophils and neutrophils; adhesion of leukocytes to vascular endothelium, monocyte and neutrophil agg regation; increased airway edema; increased capillary permeability; and bronchoconstriction. The CysLT1 receptor is found in a number of tissues including spleen, lung, placenta, small intestine, and nasal mucosa, and in a variety of cell types including monocyte/macrophages, mast cells, eosinophils, CD34positive hemopoietic progenitor cells, neutrophils and endothelial cells. 